\title{
Cyclic Oxidation Resistance of Rare Earth Oxide Gel Coated Fe-20Cr Alloys
}

\author{
Stela Maria de Carvalho Fernandes, Lalgudi Venkataraman Ramanathan* \\ Instituto de Pesquisas Energéticas e Nucleares - IPEN, \\ Av. Prof. Lineu Prestes, 2242, Cidade Universitária, 05508-000 São Paulo - SP, Brazil
}

Received: March 26, 2007; Revised: June 23, 2007

\begin{abstract}
Rare earths (RE) have been used to increase high temperature oxidation resistance of chromium dioxide and alumina forming alloys. The RE can be added as elements (or oxides) to the alloys or applied as an oxide coating to the alloy surface. RE oxide gels, obtained by the sol-gel technique, were used to coat $\mathrm{Fe}-20 \mathrm{Cr}$ specimens prior to cyclic oxidation tests in the temperature range RT- $900{ }^{\circ} \mathrm{C}$. The cyclic oxidation resistance of the alloy increased with time required to reach a specific chromium dioxide layer thickness, and this was influenced by RE ion radius, the coating morphology and coverage. Extended cyclic oxidation tests from peak temperatures of 900, 1000 and $1100{ }^{\circ} \mathrm{C}$ at cooling rates of 330 and $1000{ }^{\circ} \mathrm{C} /$ s revealed the marked influence of $\mathrm{La}_{2} \mathrm{O}_{3}$ coatings. The role of $\mathrm{RE}$ in increasing overall oxidation resistance of chromium dioxide forming alloys is discussed.
\end{abstract}

Keywords: Rare earth, rare earth oxide, sol-gel, coating, iron-chromium alloy, cyclic oxidation, chromium dioxide, morphology, coverage, ion radius, protection, scale adhesion, oxide spalling

\section{Introduction}

Materials for use in high temperature environments are usually iron, nickel or cobalt based alloys. The oxides formed on these three metals are not sufficiently protective above $500{ }^{\circ} \mathrm{C}$ and are therefore alloyed with chromium, aluminum or silicon to establish more protective oxides (scales) of chromia, alumina or silica respectively. Protective oxide scales should be non-volatile, stoichiometric to maintain low ionic transport, stress free at operating high temperatures to reduce scale failure, adherent, free of pores, cracks and other defects to prevent short circuit transport of reactants. In practice, it is almost impossible to form such ideal scales. The use of reactive elements, especially rare earths (RE) to improve high temperature oxidation resistance of chromium dioxide and alumina forming alloys is well known. The improvements are in the form of reduced oxidation rates and increased scale adhesion ${ }^{1,2}$. The RE can be added in elemental form or as oxide dispersions. It can also be applied as an oxide coating to the surface of the alloy ${ }^{2-4}$. Various precursors have been used to obtain RE oxide coatings on metallic surfaces and include aqueous nitrate solutions, molten nitrate salts, oxide slurries, or colloidal dispersions of a hydrous oxide (sol). The use of sols, followed by its transformation to gel upon removing water from the colloidal units is known to produce oxide particles (the gel) in the range $2 \mathrm{~nm}$ to $1 \mu \mathrm{m}$. The technique based on the use of sols, and referred to as the sol-gel technique, has been used to produce a variety of ceramic coatings ${ }^{5}$. The sol is applied to a metallic substrate by a suitable technique, such as dipping, spin coating or electrophoresis.

RE oxide gel coatings have the advantage of not affecting adversely the mechanical properties of the alloy and have also the potential of being used on surfaces of metallic components in service and exposed to high temperature oxidizing environments. Previous studies reported the effect of praseodymium, dysprosium and yttrium oxide gel coatings on isothermal oxidation behavior of $\mathrm{Fe}-20 \mathrm{Cr}$ alloys ${ }^{6}$. The morphology of these RE oxide coatings varied with the type of RE and the RE ion radius had an effect on the extent of chromium dioxide growth ${ }^{6}$. The effect of other rare earth oxides or rare earth oxide concentrates on oxidation behavior of chromia and alumina forming alloys showed the marked effect of rare earth oxides on chromium dioxide growth and this was more than that on alumina growth ${ }^{7,8}$. A direct correlation between the RE ion radius and the extent of protection of chromium dioxide forming alloys at temperatures up to $900{ }^{\circ} \mathrm{C}$ has been reported ${ }^{9}$. Certain RE oxide coat characteristics also had a marked effect on oxidation behavior of iron-chromium alloys 9 .

This paper presents the effect of a number of RE oxide coatings, the $\mathrm{RE}$ ion radius and other oxide coating features on the cyclic oxidation behavior of $\mathrm{Fe}-20 \mathrm{Cr}$ alloy. The effect of praseodymium oxide and lanthanum oxide as well as cooling rate from high temperatures on extended cyclic oxidation behavior of Fe-20Cr alloy is also presented. The mechanism by which REs improve overall oxidation resistance of chromium dioxide forming alloys is discussed.

\section{Methods and Materials}

In this investigation two sets of experiments were carried out. In the first set, the effect of various $\mathrm{RE}$ oxide coats $\left(\mathrm{La}_{2} \mathrm{O}_{3}, \mathrm{CeO}_{2}, \mathrm{Pr}_{2} \mathrm{O}_{3}\right.$, $\mathrm{Nd}_{2} \mathrm{O}_{3}, \mathrm{Sm}_{2} \mathrm{O}_{3}, \mathrm{Gd}_{2} \mathrm{O}_{3}, \mathrm{Dy}_{2} \mathrm{O}_{3}, \mathrm{Y}_{2} \mathrm{O}_{3}, \mathrm{Er}_{2} \mathrm{O}_{3}$, and $\mathrm{Yb}_{2} \mathrm{O}_{3}$ ) on cyclic oxidation behavior of $\mathrm{Fe}-20 \mathrm{Cr}$ alloy specimens $1.0 \times 1.0 \times 0.5 \mathrm{~cm}$ was studied. Details of the procedure used to prepare the sol and the gel coatings can be found elsewhere ${ }^{9}$. The RE oxide gel layers were about $10 \mu \mathrm{m}$ thick. The specimens were oxidized cyclically in a muffle furnace between $900{ }^{\circ} \mathrm{C}$ and room temperature. Each oxidation cycle consisted for 2 hours at $900{ }^{\circ} \mathrm{C}$. The cyclically oxidized specimens were weighed after each cycle and further oxidation of these specimens was discontinued when oxide spalling was observed. The specimen surfaces were examined between oxidation cycles and after the last oxidation cycle in an optical microscope and in a scanning electron microscope coupled to an energy dispersive spectroscopic system. In the second set of experiments, RE oxides that markedly improved the oxidation resistance of the $\mathrm{Fe}-20 \mathrm{Cr}$ alloy in the first set of experiments were chosen for further testing. New Fe-20Cr specimens coated with oxides of Pr and La were prepared for extended cyclic oxidation tests. A different experimental set up was used. A quartz glass tube containing the specimens and was held in a fixed position and the furnace, supported on a base, was moved to and fro using automatic controls. This set up permitted variations in specimen 
dwell time (in the hot and cold zones) and heating/cooling rates by controlling the speed of movement of the furnace. The Pr and La oxide coated specimens were cycled in the ranges: $900{ }^{\circ} \mathrm{C}$ - R.T., $1000{ }^{\circ} \mathrm{C}$ - R.T. $1100{ }^{\circ} \mathrm{C}$ - R.T. at cooling rates of 330 and $1000{ }^{\circ} \mathrm{C} / \mathrm{s}$.

\section{Results and Discussion}

The morphology of the RE oxide gels varied with the nature of the $\mathrm{RE}$ and the main morphological features of the different RE oxides are summarized in Table $1^{9}$.

The results of the first set of experiments are shown in Figure 1 and Table 2. The weight gain of the uncoated and RE oxide coated specimens during oxidation is due to formation of $\mathrm{Cr}_{2} \mathrm{O}_{3}$ on the specimen surfaces ${ }^{6}$. The uncoated specimen was cycled five times before the oxide scale spalled. The RE oxide coated specimens were cycled many more times, indicating increased cyclic oxidation resistance (COR) and this varied with the RE oxide. The number of cycles to spalling of the scale on specimens coated with the various RE oxides and the ratio of the radius of the $\mathrm{RE}$ ion to the radius of the chromium ion $\left(\mathrm{R}_{\mathrm{RE}} / \mathrm{R}_{\mathrm{Cr}}\right)$ are shown in Table 2. It is evident that specimens coated with $\mathrm{RE}$ oxides that had $\mathrm{R}_{\mathrm{RE}} / \mathrm{R}_{\mathrm{Cr}}$ ratios lower than 1.45 withstood only half as many cycles compared with those coated with RE oxides that had $\mathrm{R}_{\mathrm{RE}} / \mathrm{R}_{\mathrm{Cr}}$ ratios higher than 1.45 .

The chromium dioxide layer on specimens coated with La and Pr oxides did not spall even after 15 cycles. The weight gains of these specimens after one cycle and after 15 cycles were low and about $0.17 \mathrm{mg} \cdot \mathrm{cm}^{-2}$. After one cycle of oxidation the weight gain of the $\mathrm{La}_{2} \mathrm{O}_{3}$ coated specimen was one quarter that of the specimen coated with $\mathrm{Yb}_{2} \mathrm{O}_{3}$. A significant part of the weight gain of specimens

Table 1. Main morphological feature of the rare earth oxides.

\begin{tabular}{ll}
\hline Rare earth oxide & Main morphological feature \\
\hline Lanthanum & Cubes and rods \\
Cerium & Cubes \\
Praseodymium & Cuboids \\
Neodymium & Fine needles, acicular \\
Samarium & Clusters \\
Gadolinium & Interlocking clusters \\
Dysprosium & Tiny clusters \\
Yttrium & Platelets \\
Erbium & Open clusters \\
Ytterbium & Clusters and disperse platelets \\
\hline
\end{tabular}

Table 2. Number of oxidation cycles withstood before spalling and the ratios of the $\mathrm{RE}$ ion radius to the radius of chromium ion.

\begin{tabular}{lcc}
\hline \multicolumn{1}{c}{ Oxide of } & Number of cycles at spall & $\mathrm{R}_{\mathrm{RE}} / \mathrm{R}_{\mathrm{Cr}}$ ratio \\
\hline Lanthanum & $15+$ & 1.64 \\
Cerium & 9 & 1.60 \\
Praseodymium & $15+$ & 1.57 \\
Neodymium & 12 & 1.54 \\
Samarium & 12 & 1.50 \\
Gadolinium & $15+$ & 1.46 \\
Dysprosium & 6 & 1.42 \\
Yttrium & 7 & 1.39 \\
Erbium & 7 & 1.37 \\
Ytterbium & 4 & 1.34 \\
\hline
\end{tabular}

coated with $\mathrm{La}_{2} \mathrm{O}_{3}$ and $\operatorname{Pr}_{2} \mathrm{O}_{3}$, due to chromium dioxide growth, occurred during the first cycle of oxidation. In general, spalling of the chromium dioxide layer occurred when weight gains were above 1.25-1.5 mg. $\mathrm{cm}^{-2}$. This indicates that the time at temperature to reach a specific chromium dioxide layer thickness varied with the nature of RE. On the basis of these data, the oxides of Pr and La were selected for the second set of experiments to determine their influence on oxidation behavior of $\mathrm{Fe}-20 \mathrm{Cr}$ alloys in extended cyclic oxidation tests with varying cooling rates. The results of these tests are shown in Table 3.

The COR of both the uncoated and RE oxide coated specimens decreased with increase in the peak temperature. This behavior did not change with cooling rate. At low and high cooling rates from $900{ }^{\circ} \mathrm{C}$ the $\mathrm{La}_{2} \mathrm{O}_{3}$ coated specimens could be cycled for over 100 and 47 cycles respectively. This was significantly higher than the COR of the $\operatorname{Pr}_{2} \mathrm{O}_{3}$ coated specimens under identical conditions. In the case of the $\mathrm{La}_{2} \mathrm{O}_{3}$ coated specimens, increase in peak temperature from 900 to $1000{ }^{\circ} \mathrm{C}$ decreased the COR by approximately $33 \%$. A further increase in peak temperature to $1100{ }^{\circ} \mathrm{C}$ decreased $\mathrm{COR}$ by a further $33 \%$. Even though the high cooling rate tests of $\mathrm{La}_{2} \mathrm{O}_{3}$ coated specimens from $900{ }^{\circ} \mathrm{C}$ were discontinued, the overall COR of $\mathrm{La}_{2} \mathrm{O}_{3}$ coated $\mathrm{Fe}-20 \mathrm{Cr}$ did not alter with increase in cooling rate from 330 to $1000{ }^{\circ} \mathrm{C} / \mathrm{s}$.

\section{General Discussion}

The morphology of the different RE oxide gels revealed marked differences ${ }^{3,9}$. Correlations between the morphology of the RE oxide and the COR of coated Fe-20Cr alloy have been reported ${ }^{9}$. Specimens

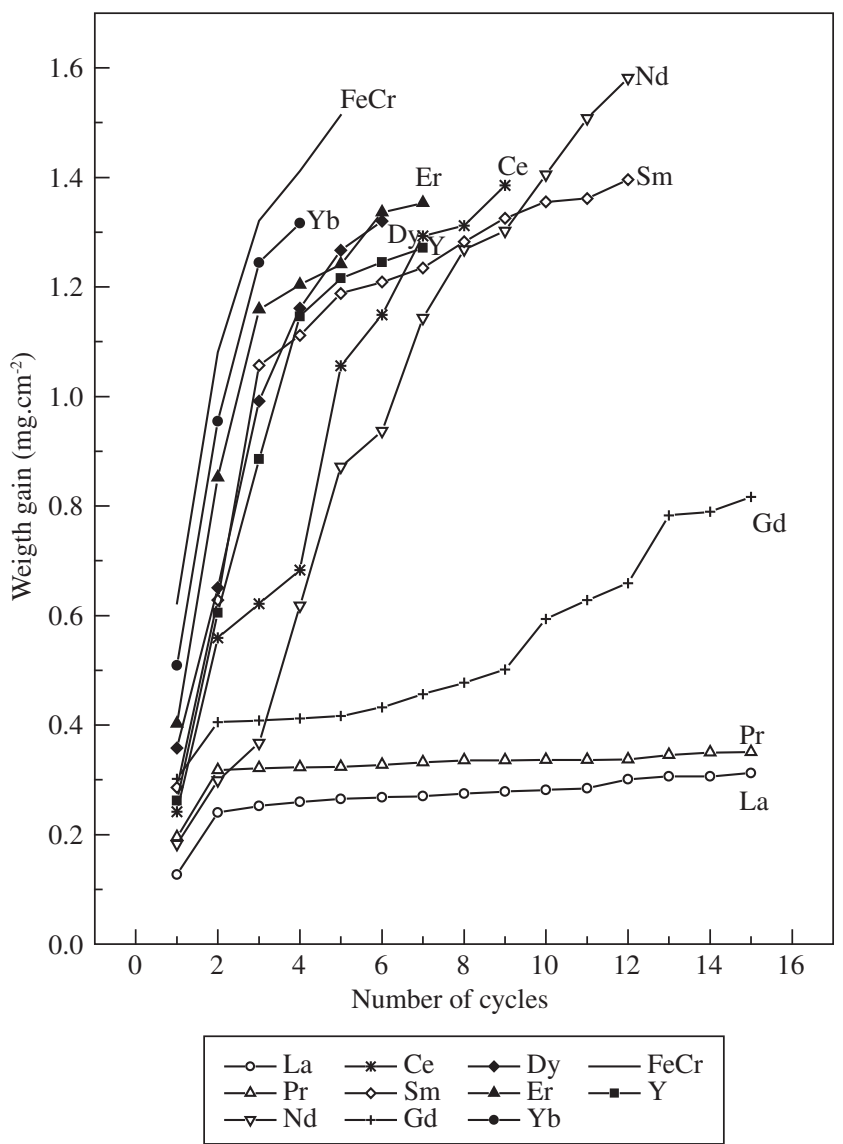

Figure 1. Weight gain vs. number of cycles of oxidation of $\mathrm{Fe}-20 \mathrm{Cr}$ alloy without and with surface deposited RE oxide. 
Table 3. Cyclic oxidation resistance of uncoated, $\mathrm{La}_{2} \mathrm{O}_{3}$ coated and $\operatorname{Pr}_{2} \mathrm{O}_{3}$ coated Fe-20Cr specimens.

\begin{tabular}{|c|c|c|c|c|c|c|}
\hline \multirow[t]{3}{*}{$\mathrm{Fe}-20 \mathrm{Cr}$ specimen } & \multicolumn{6}{|c|}{ Number of cycles to spalling } \\
\hline & \multicolumn{3}{|c|}{ Low cooling rate $\left(330^{\circ} \mathrm{C} / \mathrm{s}\right)$} & \multicolumn{3}{|c|}{ High cooling rate $\left(1000^{\circ} \mathrm{C} / \mathrm{s}\right)$} \\
\hline & $900^{\circ} \mathrm{C}$ & $1000{ }^{\circ} \mathrm{C}$ & $1100{ }^{\circ} \mathrm{C}$ & $900{ }^{\circ} \mathrm{C}$ & $1000^{\circ} \mathrm{C}$ & $1100{ }^{\circ} \mathrm{C}$ \\
\hline Uncoated & 11 & 7 & 3 & 5 & 5 & 3 \\
\hline $\mathrm{Pr}_{2} \mathrm{O}_{3}$ coated & 15 & 12 & 6 & 11 & 11 & 5 \\
\hline $\mathrm{La}_{2} \mathrm{O}_{3}$ coated & 102 & 32 & 11 & $>47$ & 30 & 11 \\
\hline
\end{tabular}

coated with RE oxides with cube, rod or needle-like morphology withstood a higher number of oxidation cycles compared to those coated with RE oxides with platelet or cluster morphology ${ }^{9}$. Coverage or the extent to which the Fe-20Cr surface was covered by the different RE oxides also varied and correspondence between coverage and COR has been reported 9 .

The COR of Fe-20Cr alloy coated with RE oxide gels varied and it was shown that COR depends on the thickness of the chromium dioxide layer formed on the alloy surface. In the presence of an RE oxide coating the chromium dioxide layer formed after the first cycle of oxidation is thinner than that on surfaces without a RE oxide coating and it varied with RE oxide. Spalling of the chromium dioxide layer, which marks the breakdown of COR, occurs when its thickness reaches a critical value. Hence, the longer it takes to reach this critical oxide scale thickness, higher the COR. Characteristics of the RE oxide coating that affect the time required to reach this critical oxide scale thickness are the ionic radii of the RE, the shape and size of the $\mathrm{RE}$ oxide crystallites and the coverage.

In the initial or transient stage of oxidation, metastable oxides of base metals such as iron oxide, form on the alloy surface ${ }^{1}$. The effects of RE on scale growth are not evident at this stage ${ }^{1-4}$. The addition of $\mathrm{RE}$ in elemental form has been shown to influence chromia growth rate more than alumina growth rate ${ }^{7,8}$. The use of RE oxide coats on $\mathrm{Cr}$ or $\mathrm{Al}$ containing alloys affects chromia and alumina growth in the same manner as when RE elements are added to the alloy ${ }^{7,8}$. Some of the REs exercise greater influence than others ${ }^{9}$. Figure 2 shows schematically chromia growth in the absence and presence of RE. In the absence of RE in the alloy or on the surface, the new oxide scale grows at the oxide /oxygen interface and in the presence of RE it grows at the metal/oxide interface.

In the case where REs are added to the alloy, the reactive elements in the alloy diffuse into the scale due to the oxygen potential gradient which extends from the gas interface into the substrate. The RE diffuses through the oxide to the gas interface. Proof of this was shown after prolonged oxidations ${ }^{8}$. En-route to the gas interface the RE ions first segregate to the metal-scale interface and then these RE ions follow the fastest path to the gas interface, which are the scale grain boundaries ${ }^{10-16}$. This is shown schematically in Figure $3^{8}$. The RE oxides applied as coatings to the alloy surface is incorporated in the growing scale, as observed in this study ${ }^{7}$. Their ions segregate to the scale grain boundaries. When the RE ion concentration at the grain boundaries reaches a critical amount it results in the two effects observed in this study.

The first effect is inhibition of normal outward short-circuit transport of cations along the scale grain boundaries due to the slower diffusion of the large RE ions compared with the $\mathrm{Cr}$ ions. It is also probable that larger the RE ion, slower its outward diffusion to the oxide/gas interface. This indicates that the RE ions block outward grain boundary diffusion of $\mathrm{Cr}$ ions in chromia. Proof of this was reported earlier ${ }^{6}$. Similar observations were presented by Papaiacovou et al. for scale growth on ceria coated $\mathrm{Fe}-\mathrm{Cr}$ alloys ${ }^{17}$. The $\mathrm{RE}$ ions are significantly larger than $\mathrm{Fe}$ or $\mathrm{Cr}$ ions, and their ionic radii are 1.3 to 1.65 times that of $\mathrm{Cr}$. The extents to which RE elements affect

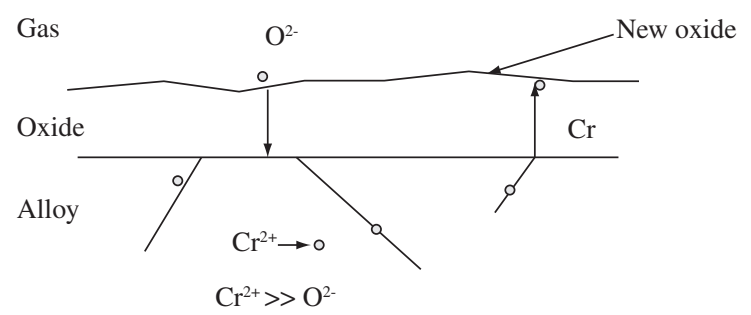

(a)

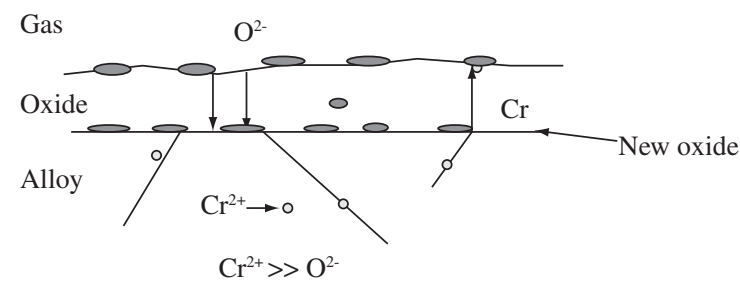

(b)

Figure 2. Schematic diagram of chromia growth: a) in the absence of RE oxide; and b) with RE oxide coating.

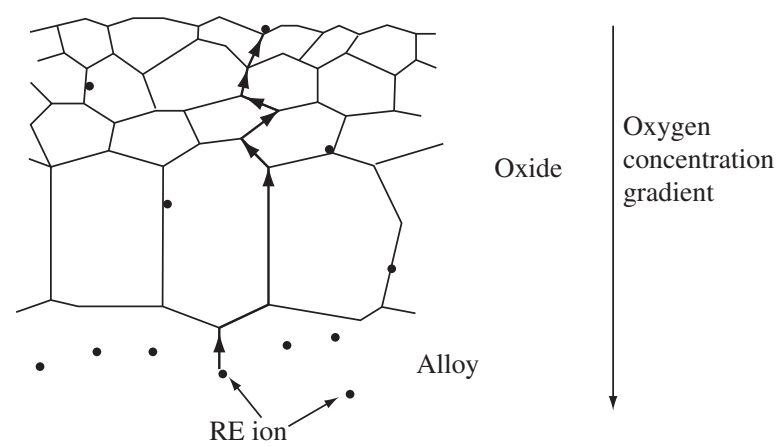

Figure 3. Schematic diagram showing RE ion diffusion along chromia scale grain boundaries.

oxidation rates have been found to be proportional to their sizes ${ }^{6}$. The larger the RE ion, greater its influence. Direct correlation between $\mathrm{RE}$ ion radius and cyclic oxidation resistance has been found. As a result, the new rate-limiting step is the inward transport of $\mathrm{O}^{-}$ions along the scale grain boundaries. Inhibition of the outward transport of alloy cations results in a reduction in the parabolic rate constant. This has been observed and reported ${ }^{7,8}$.

The second effect is reduction in scale grain growth and this is due a solute-drag effect of the RE ions on the scale grain boundaries ${ }^{18}$. This results in a smaller average grain size in $\alpha-\mathrm{Cr}_{2} \mathrm{O}_{3}$ scales and higher scale plasticity ${ }^{19}$. Reactive-element induced improvements in scale 
adhesion are due to segregation of RE ions to the metal-scale interface and reduction in the quantity of voids ${ }^{8}$. Normally voids form due to perturbations at the metal-scale interface and these perturbations could be due to defects in the scale or the metal, grain growth in the metal or scale, diffusion, vacancy condensation or surface roughness. Segregation of RE ions does not eliminate void nucleation at the metal-scale interface, but it prevents them from growing rapidly and the metal-scale adhesion is maintained for a longer period ${ }^{7,8}$. In general, spalling occurs when scale thickness, reflected as mass gains per unit area in oxidation measurements is above a certain value. This was found to be $1.25-1.5 \mathrm{mg} . \mathrm{cm}^{-2}$ for chromia growth in this study. This indicated that the time at temperature to reach a specific chromia layer thickness varied with the nature of RE.

The higher COR of Fe-20Cr coated with $\mathrm{La}_{2} \mathrm{O}_{3}$, compared with that coated with $\operatorname{Pr}_{2} \mathrm{O}_{3}$, or any other RE oxide is further proof of the effect of the RE ion size. In this case the time taken to form the critical chromia layer thickness is significantly longer. The scale formed is thin, more plastic, more adherent to the alloy and therefore capable of withstanding stresses associated with scale growth and temperature cycling.

\section{Conclusions}

1. The COR of RE oxide coated Fe-20Cr alloy was significantly higher than that of the uncoated alloy;

2. The chromium dioxide layer thickness on the RE oxide coated $\mathrm{Fe}-20 \mathrm{Cr}$ alloy varied with the RE oxide;

3. The COR varied with the type of RE oxide;

4. The COR of $\mathrm{Fe}-20 \mathrm{Cr}$ coated with $\mathrm{La}_{2} \mathrm{O}_{3}$ was significantly higher than that of the same alloy coated with $\operatorname{Pr}_{2} \mathrm{O}_{3}$;

5. The COR of $\mathrm{La}_{2} \mathrm{O}_{3}$ coated $\mathrm{Fe}-20 \mathrm{Cr}$ was unaffected with increase in cooling rate from 330 to $1000{ }^{\circ} \mathrm{C} / \mathrm{s}$; and

6 . Further evidence of a direct correlation between $\mathrm{RE}$ ion radius and oxidation resistance of chromia forming alloys has been observed.

\section{References}

1. Stott FH. Influence of alloy additions on oxidation. Materials Science and Technology. 1989; 5(8):734-740.

2. Stringer J. The reactive elements effect in high temperature corrosion. Materials Science and Engineering. 1989; A120:129-137.

3. Hou PY, Stringer J. The effect of surface applied reactive metal oxide on the high temperature oxidation of alloys. Materials Science and Engineering. 1987; 87(Part 1):295-302.
4. Ramanathan LV. Role of rare earth elements on high temperature oxidation behavior of $\mathrm{Fe}-\mathrm{Cr}, \mathrm{Ni}-\mathrm{Cr}$ and $\mathrm{Ni}-\mathrm{Cr}-\mathrm{Al}$ alloys. Corrosion Science. 1993; 35(5-8):871-878.

5. Bennett MJ. New coatings for high temperature materials protection. Journal of Vacuum Science and Technology. 1984; B2(4):800-805.

6. Fernandes SMC, Ramanathan LV. Influence of rare earth oxide coatings on oxidation behavior of Fé-20Cr alloys. Surface Engineering. 2000; 16(4):327-332.

7. Fernandes SMC, Pillis MF, Ramanathan LV. Role of Rare Earth Oxide Coatings on Oxidation Resistance of Chromia Forming Alloys. Journal of Materials Science; 2007. (In press).

8. Pint B. Experimental Observations in Support of the Dynamic-Segregation Theory to Explain the Reactive-Element Effect. Oxidation of Metals. 1996; 45(1-2):1-37.

9. Fernandes SMC, Ramanathan LV. Effect of Surface Deposited Rare Earth Oxide Gel Characteristics on Cyclic Oxidation Behavior of Fe20-Cr alloys. Materials Research. 2006; 9(2):199-203.

10. Cotell CM, Yurek GJ, Hussey RJ, Mitchell DF, Graham MJ. The Influence of Grain Boundary Segregation of Yttrium in Chromium Dioxide on the Oxidation of Chromium Metal. Oxidation of Metals. 1990; 34(3-4):173-200

11. Versaci RA, Clemens D, Quadakkers WJ, Hussey R. Distribution and transport of yttrium in alumina scales on iron-base ODS alloys. Solid State Ionics. 1993; 59(3):235-242.

12. Pint B, Martin JR, Hobbs LW. ${ }^{18} \mathrm{O} /$ SIMS Characterization of the Growth Mechanism of Doped and Undoped $\alpha-\mathrm{Al}_{2} \mathrm{O}_{3}$. Oxidation of Metals. 1993; 39(3-4):167-195.

13. Pint B, Hobbs LW. The Formation of $\alpha-\mathrm{Al}_{2} \mathrm{O}_{3}$ Scales at $1500{ }^{\circ} \mathrm{C}$. Oxidation of Metals. 1994; 41(3-4):203-233.

14. Pint B, Hobbs LW, Limitations on the use of Ion Implantation for the Study of the Reactive Element Effect in $\beta$-NiAl. J. Electrochem. Soc. 1994; 141(9):2443-2453.

15. Pint B, Hobbs LW. In Horton J, Hanada S, Baker I, Noebe RD, Schwartz D, eds. High Temperature Ordered Intermetallics VI, Symp. Proc., v. 364. MRS: Pittsburgh, PA; 1995; p. 987-992.

16. Pint B, Garratt-Reed AJ, Hobbs LW. The Reactive Element Effect in ODS FeCrAl Alloys. Materials at High temperatures. 1995; 13:3-16.

17. Papaiacovou P, Hussey RJ. The effect of $\mathrm{CeO}_{2}$ coatings on the oxidation behavior of Fe-20Cr alloys in $\mathrm{O}_{2}$ at $1173 \mathrm{~K}$. Corrosion Science. 1990; 30(4/5):451-460.

18. Kingery WD, Bowen HK, Uhlmann DR. Introduction to Ceramics. Wiley, New York; 1976. p. 457.

19. Ramanarayanan TA, Raghavan M, Petkovic-Luton R, The Characteristics of Alumina Scales Formed on Fe-based Yttria-Dispersed Alloys. $J$. Electrochem. Soc. 1984; 131(4):923-931. 